\title{
Speed distribution and traffic safety measures
}

\author{
Anna Vadeby ${ }^{*}$ and $\AA$ sa Forsman ${ }^{\dagger}$ \\ Swedish National Road and Research Institute, SE-58195 Linköping, Sweden
}

\begin{abstract}
A main traffic safety priority in many countries is implementing measures that reduce road user speed and increase speed limit compliance. This study compares changes in the speed distribution and estimated accident risk brought about by three measures: speed limit change from 110 to $100 \mathrm{~km} / \mathrm{h}$ on roads without speed cameras, speed limit change from 90 to $80 \mathrm{~km} / \mathrm{h}$ on roads with speed cameras, and introducing new speed cameras on roads with a speed limit of $90 \mathrm{~km} / \mathrm{h}$. The accident risk is estimated from mean speed since the impacts of a change in mean speed on the number of accidents and of injured and killed people are well known. The results indicate that installing speed cameras can reduce average speed more than can reducing the speed limit by 10 $\mathrm{km} / \mathrm{h}$, at least at the camera locations. Moreover, speed cameras reduce the standard deviation of speed and the percentage of drivers exceeding the speed limit by far more than does lowering the mean speed. This implies that the relationship between change in speed distribution, not only mean speed, and traffic safety merits further investigation.
\end{abstract}

Keywords: traffic safety, speed, accident risk, speed distribution.

\section{Résumé}

Une priorité principale de la sécurité routière dans de nombreux pays est de mettre en place des mesures permettant la réduction de la vitesse des usagers de la route et d'accroître leur respect des limites de vitesse. Cette étude compare les changements dans la répartition des limites de vitesse et une estimation du risque d'accident grâce à trois scénarios: des changements de limite de vitesse de 110 à $100 \mathrm{~km} / \mathrm{h}$ sur les routes sans radars, des changements de limite de vitesse de 90 à $80 \mathrm{~km} / \mathrm{h}$ sur les routes avec radars, et l'introduction de nouveaux radars sur les routes où la limite de vitesse est de $90 \mathrm{~km} / \mathrm{h}$. Le risque d'accident est estimé à partir de la vitesse moyenne puisque les impacts d'un changement de vitesse moyenne sur le nombre d'accidents, de blessés et tués sont bien connus. Les résultats indiquent que l'installation de radar serait plus efficace pour réduire la vitesse moyenne qu'une réduction de la limite de vitesse de $10 \mathrm{~km} / \mathrm{h}$, au moins au niveau des emplacements des radars. Par ailleurs, la mise en place de radar réduirait d'avantage l'écart type de la vitesse et le pourcentage de conducteurs dépassant les limites de vitesse que la réduction de celles-ci. Cela implique que la relation entre les changements dans la distribution de vitesse, pas seulement la vitesse moyenne, et la sécurité routière mérite une enquête plus approfondie.

Mots-clé: sécurité routière, vitesse, risque d'accident, distribution de vitesse

\footnotetext{
*Tel.: +46 709430 488; fax: +46 13 141436. E-mail address:anna.vadeby@ vti.se

† Tel.: +46 709430 419; fax: +46 13 141436. E-mail address: asa.forsman@ vti.se.
}

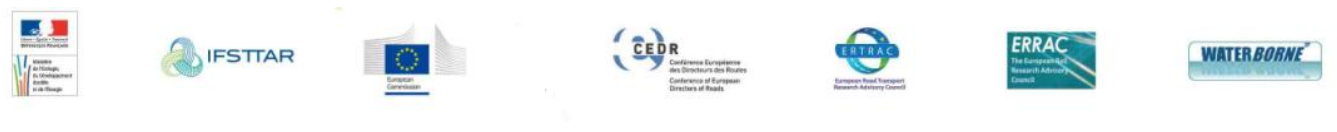




\section{Introduction and aim of the study}

It is well known that speed is a crucial road safety factor. Many implemented safety measures aim to induce road users to reduce their speed and comply with speed limits. As regards the change in mean speed, the impacts on road safety in terms of number of accidents and the number of injured and killed people are well known. This relationship is, for example, described by the Power model (Elvik et al., 2004; Nilsson, 2004), which is often used to estimate the traffic safety effects of speed changes. However, it is not certain that only the mean speed is affected by particular traffic safety measures; measures such as the 85th percentile, standard deviation of speed, and shape of the speed distribution can also be affected.

This study investigates and compares the changes in speed distribution and estimated accident risk for three traffic safety measures:

- speed limit change from 110 to $100 \mathrm{~km} / \mathrm{h}$ on rural roads without speed cameras

- speed limit change from 90 to $80 \mathrm{~km} / \mathrm{h}$ on rural roads with speed cameras

- introducing new speed cameras on rural roads with a speed limit of $90 \mathrm{~km} / \mathrm{h}$.

The Power model is applied to aggregate data from a road site, but other models estimate how speed affects accident risk at the individual level (Aarts and Schagen, 2006). Several studies in the 1960s (Cirillo, 1968; Solomon, 1964) analysed individual risks in relation to the choice of speed and found a U-shaped relationship between speed and accident risk. More recent studies suggest that the relationship increases fairly monotonically, the slope becoming steeper at higher speeds (Kloeden et al., 2001; Maycock et al., 1998; Quimby et al., 1999). This means that the higher the driving speed, the higher the risk of being involved in an accident. However, overall risk does not increase if one drives below the average speed on the road. Different studies have come up with quite different sizes of the increased risk when driving above the average speed, and there is still considerable uncertainty as to the actual appearance of the individual risk curve.

The different models described by Aarts and Schagen (2006) reflect different views of how speed affects accident risk. In somewhat simplified terms, one approach claims that the speed itself is most important, while the second approach claims that speed variation between vehicles on the same road is most important. The main argument supporting the first approach is that increased speed causes longer reaction times and stopping distances if something unexpected happens, and that increased speed leads to more serious consequences if an accident does occur. One argument supporting the second view is that large variations in speed between adjacent vehicles give rise to conflicts, which in turn can lead to accidents. Shinar (1998) describes the two views in great detail. One aspect highlighted in several studies is that speed variation is probably relevant only to certain types of accidents, while absolute speed affects every accident. Another difficulty when distinguishing between the effects of mean speed and speed variation is that these variables are highly correlated (Andersson and Nilsson, 1997; Finch et al., 1994; Shinar, 1998), making it difficult to isolate the effects of speed from those of speed variation.

This study seeks a better understanding of the relationship between traffic safety measures and speed distribution, to obtain a better basis for planning and evaluating various road safety measures. Changes in estimated accident risk are calculated using the Power model (Elvik et al., 2004; Nilsson, 2004). However, our aim is not to estimate the absolute traffic safety effect of these measures, but to illustrate how the speed distribution and various related measures, such as the 85th percentile and standard deviation of speed, can change due to these measures. 


\section{Method}

Speed limit changes and speed enforcement are two available measures to reduce road users' speed. Here, decreased speed limits on roads with and without speed cameras and the introduction of new speed cameras are examined.

\subsection{Data}

To perform the study, speed data from two sources were used: a national evaluation of new speed limits in Sweden and an evaluation of movable speed cameras. The speed of all vehicles were considered in the analyses.

\section{National evaluation of new speed limits}

Between 2008 and 2011, the Swedish Transport Administration reviewed the speed limits on the state rural road network in Sweden. Guidelines were established for different types of roads, and the long-term vision was that speed limits should be adapted to the safety classification of each road. A new set of speed limits (i.e. 80, 100, and $120 \mathrm{~km} / \mathrm{h}$ ) was introduced on rural roads to complement the previously used limits of 70, 90, and $110 \mathrm{~km} / \mathrm{h}$. Earlier studies have investigated the effects of the new speed limits on the rural road network (Vadeby and Forsman 2013; Vadeby and Forsman, 2010; Vadeby and Forsman 2012a). In the present study, we re-use speed data collected in the national evaluation of new speed limits; these speed data come from both tube measurements and speed cameras.

The aim is to illustrate how the speed distribution and other measures (such as mean speed) can be changed on roads where the speed limit is lowered, not to estimate the total effect on the network. Therefore, on roads where the speed limit was decreased from 110 to $100 \mathrm{~km} / \mathrm{h}$, the eight sites with the greatest speed reduction (of a total of 20 sites) were selected. The measurements are from $2+1$ roads (i.e., continuous three-lane roads with alternating passing lanes and the two directions of travel separated by a flush divider with a median barrier) and standard two-lane rural roads. At each measurement site, the measurements were made both before (August, 2008) and one year after (August, 2009) the new speed limit was instituted. To be considered an acceptable measurement, the speed at each road site had to be measured for at least three whole weekdays between noon Monday and noon Friday, and the presented results had to represent daytime conditions, i.e., from 06.00 to 20.00. The speed of passing vehicles was measured using pneumatic tubes stretched across the road. Overall, speeds were registered from approximately 47,000 vehicles in 2008 and approximately 59,000 vehicles in 2009. For a more detailed description of the data collection, see Vadeby and Forsman (2013).

Speed data from speed cameras (radar) come from three sites. The speed limits at these sites were $90 \mathrm{~km} / \mathrm{h}$ before the speed limit change and $80 \mathrm{~km} / \mathrm{h}$ after. Speed data were collected both before (August, 2008) and after (August, 2009) the new speed limit was instituted. In total, speeds from approximately 66,000 vehicles were registered both before and after the new limit.

\section{Evaluation of movable speed cameras}

In 2010, moveable speed cameras were trialled on five road stretches in Sweden. Along each stretch, nine fixed mountings were installed on which cameras could easily be mounted. The idea was to move three cameras around between the nine mountings, so that road users could not be sure where the cameras were located. Warning signs were placed a few hundred meters before the mountings, regardless of whether or not there were cameras mounted on them.

This study uses speed data from six sites, all of which had a camera in place for the after measurements. All sites were on rural roads with a speed limit of $90 \mathrm{~km} / \mathrm{h}$. Speed data were collected using pneumatic tubes stretched across the road. The speed measurements used here were made before (August/September, 2010) and after (September/October, 2010) the speed cameras were installed. At each site and on each measurement occasion, the speeds of passing vehicles were registered for one week. In total, the speeds of approximately 115,000 vehicles were registered per occasion (before and after). Only speeds of vehicles travelling in the direction of the camera orientation were considered. 


\subsection{Measures}

It is unclear in the literature what measure is the most appropriate to use when studying the relationship between speed and road safety, although mean speed and/or the standard deviation of speed are often calculated. Other dimensions, such as the 85th percentile, variance, coefficient of variation, of drivers exceeding the speed limit, and the mean speed of those exceeding the speed limit, are also proposed in the literature (Aarts and van Schagen, 2006). To characterize how the speed of all vehicles varies, one can study the speed distribution, which indicates the proportions of vehicles driving at certain speeds. Besides the speed distribution, the following measures are considered here (Table 1):

Table 1. Description of measures

\begin{tabular}{ll}
\hline Measure & Description \\
\hline Mean speed & Arithmetic mean speed \\
Standard deviation of speed & \\
Coefficient of variation & Ratio between mean speed and standard deviation \\
Mean speed of those obeying speed limit & \\
Mean speed of those exceeding speed limit & \\
Percentage exceeding speed limit & \\
Percentage exceeding speed limit by $6 \mathrm{~km} / \mathrm{h}$ or more & \\
Percentage exceeding speed limit by $30 \mathrm{~km} / \mathrm{h}$ or more & \\
P85 & Speed exceeded by $15 \%$ of drivers \\
P15 & Speed exceeded by $85 \%$ of drivers \\
\hline
\end{tabular}

\subsection{The Power model}

The changes in accident risks are calculated using the Power model (Elvik et al., 2004; Nilsson, 2004), according to which the relative speed changes affect the number of accidents or injured people, $y_{A}$, as follows:

$\frac{y_{A}}{y_{B}}=\left(\frac{v_{A}}{v_{B}}\right)^{d}$

where $y_{B}$ is the number of accidents or injured people before the speed change, $v_{B}$ and $v_{A}$ are the mean speeds before and after the speed change, and the power $d$ depends on the outcome of interest. The powers are set according to Elvik et al. (2004) and are $d=4.5$ for the number of fatal, $d=3.0$ for the number of severe, and $d=$ 1.5 for the number of minor injuries.

\section{Results}

\subsection{Speed distribution}

Figs. 1-3 show the speed distributions before and after the following three traffic safety measures:

- speed limit change from 110 to $100 \mathrm{~km} / \mathrm{h}$ on rural roads without speed cameras

- speed limit change from 90 to $80 \mathrm{~km} / \mathrm{h}$ on rural roads with speed cameras

- introducing new speed cameras on rural roads with a speed limit of $90 \mathrm{~km} / \mathrm{h}$.

The figures cover all vehicles passing all measurement sites for each safety measure. Note that these examples are intended to illustrate simply how the speed distributions change for different safety measures and should not be viewed as illustrating the general effects of the measures. Fig. 1 shows that as the speed limit was lowered from $110 \mathrm{~km} / \mathrm{h}$ (red curve) to $100 \mathrm{~km} / \mathrm{h}$ (blue curve), the entire speed distribution shifted to the left, indicating a general speed decrease. The biggest change occurred in the mid-speed range, while the changes were smaller at speeds below $90 \mathrm{~km} / \mathrm{h}$. The percentage of vehicles travelling below the speed limit declined from approximately $70 \%$ to approximately $50 \%$. 


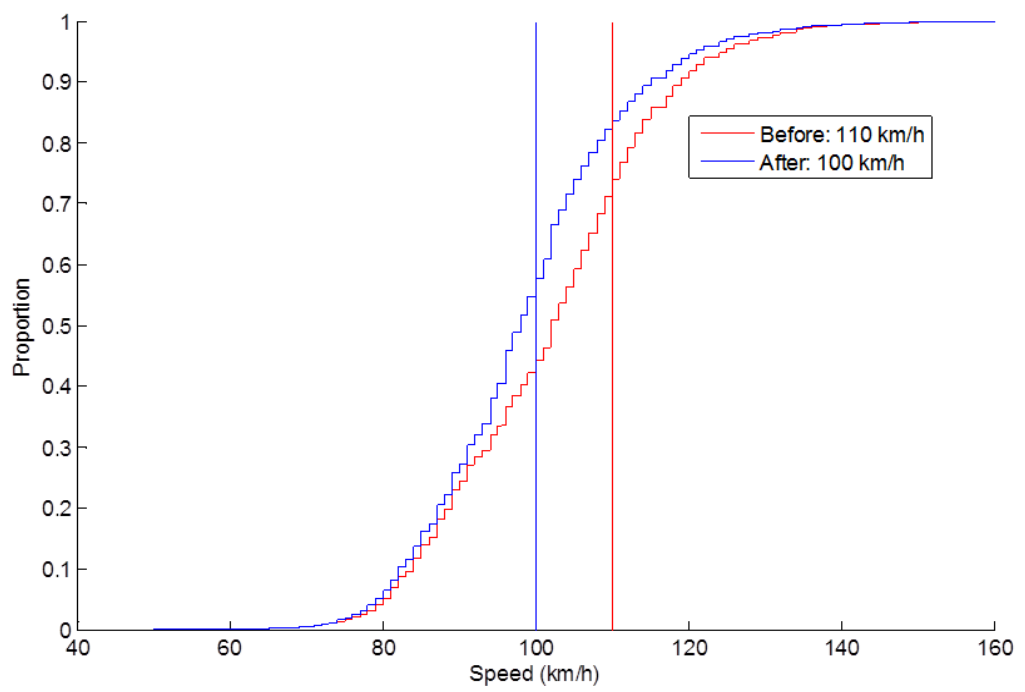

Fig. 1. Speed limit change from 110 to $100 \mathrm{~km} / \mathrm{h}$ on rural roads without speed cameras. Speed distribution for all cars before and after new speed limit $100 \mathrm{~km} / \mathrm{h}$.

Fig. 2 shows how the speed distribution changed when the speed limit was lowered from 90 to $80 \mathrm{~km} / \mathrm{h}$ on roads with speed cameras. Compared with Fig. 1, the speed distribution is more upright both before and after the speed limit was lowered and the speed limit compliance is much better. Approximately $95 \%$ of the road users complied with the speed limit before the change and approximately $85 \%$ afterwards. One should also note the relatively large shift to the left even at speeds under the new speed limit of $80 \mathrm{~km} / \mathrm{h}$, possibly because speedometers tend to overestimate the speed.

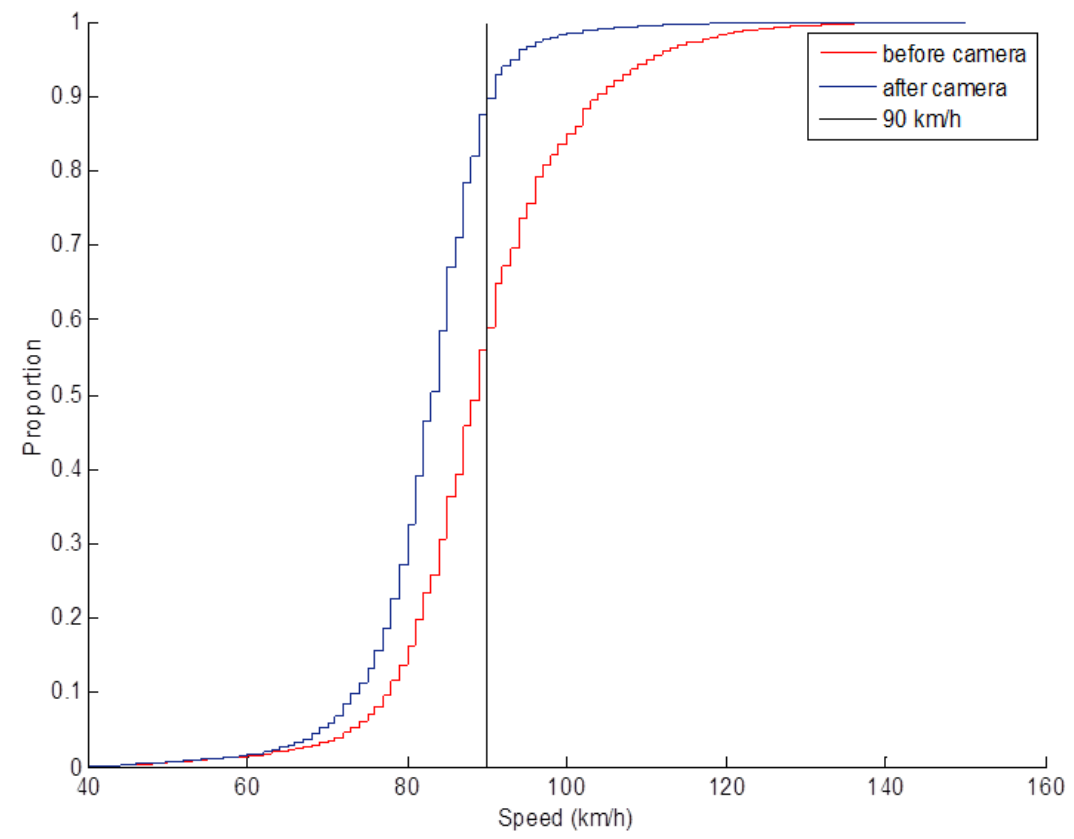

Fig. 2. Speed limit change from 90 to $80 \mathrm{~km} / \mathrm{h}$ on rural roads with speed cameras. Speed distribution for all cars before and after new speed limit $80 \mathrm{~km} / \mathrm{h}$. 


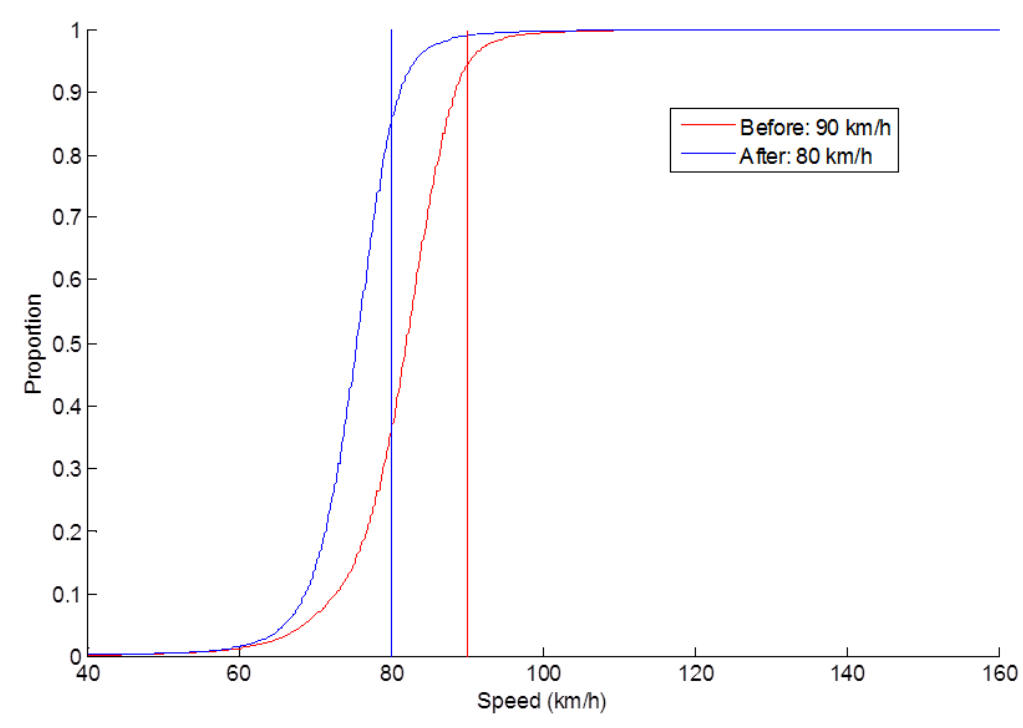

Fig. 3. Introducing new speed cameras on roads with a speed limit of $90 \mathrm{~km} / \mathrm{h}$. Speed distribution for all cars before and after new cameras.

Fig. 3 illustrates what can happen to the speed distribution when speed cameras are introduced on a rural road with a speed limit of $90 \mathrm{~km} / \mathrm{h}$. This distribution displays a larger displacement to the left (i.e., towards lower speeds) at high speeds, meaning that those driving at the highest speeds reduced their speed the most. As in Fig. 2 , one can also see that this distribution moves to the left even for speeds that, before the change, were already within the new speed limit. The figure indicates that approximately $90 \%$ of the drivers drove within the speed limit after the introduction of speed cameras, while before it was approximately $60 \%$.

\subsection{Speed measures}

In addition to the speed distributions, the levels of various measures before and after camera installation or speed limit changes as well as the absolute and relative changes in the measures are shown in Tables 2-4. Table 2 shows that the mean speed decreased by more than $3 \mathrm{~km} / \mathrm{h}$ when the speed limit was lowered from 110 to 100 $\mathrm{km} / \mathrm{h}$, representing a decrease of approximately $3 \%$. The change in the standard deviation of speed was slightly greater, approximately $7 \%$, so the coefficient of variation has decreased. The mean speed decreased slightly more at speeds above the current speed limit than at those under the current limit. This is also reflected in the percentiles, where the speed reduction is greater for the 85th percentile (P85) than for the 15th percentile (P15). This result was expected, because those who were already driving below the new speed limit had no incentive to reduce their speed further. The percentage of drivers exceeding the speed limit increased from 0.26 to 0.42 , while the percentage of those exceeding the limit by more than $6 \mathrm{~km} / \mathrm{h}$ increased from 0.14 to 0.24 . Looking at the relative change, the increases in these measures are of the same magnitude. Few people drive more than 30 $\mathrm{km} / \mathrm{h}$ above the speed limit, so these changes should be carefully interpreted. 
Table 2. Change in various measures when the speed limit was decreased from 110 to $100 \mathrm{~km} / \mathrm{h}$ on rural roads without speed cameras.

\begin{tabular}{|c|c|c|c|c|}
\hline Measure & Before & After & $\begin{array}{l}\text { Change: after- } \\
\text { before }\end{array}$ & $\begin{array}{l}\text { Relative change } \\
(\%)\end{array}$ \\
\hline Mean speed $(\mathrm{km} / \mathrm{h})$ & 101.7 & 98.6 & -3.1 & $-3 \%$ \\
\hline Standard deviation of speed $(\mathrm{km} / \mathrm{h})$ & 14.1 & 13.1 & -1.0 & $-7 \%$ \\
\hline Coefficient of variation & 0.14 & 0.13 & -0.01 & $-4 \%$ \\
\hline $\begin{array}{l}\text { Mean speed of those obeying speed limits } \\
(\mathrm{km} / \mathrm{h})\end{array}$ & 95.6 & 89.9 & -5.7 & $-6 \%$ \\
\hline $\begin{array}{l}\text { Mean speed of those exceeding speed } \\
\text { limits }(\mathrm{km} / \mathrm{h})\end{array}$ & 119.1 & 110.4 & -8.7 & $-7 \%$ \\
\hline Percentage exceeding speed limits & $26 \%$ & $42 \%$ & $16 \%$-points & $62 \%$ \\
\hline $\begin{array}{l}\text { Percentage exceeding speed limits by } 6 \\
\mathrm{~km} / \mathrm{h} \text { or more }\end{array}$ & $14 \%$ & $24 \%$ & $10 \%$-points & $69 \%$ \\
\hline $\begin{array}{l}\text { Percentage exceeding speed limits by } 30 \\
\mathrm{~km} / \mathrm{h} \text { or more }\end{array}$ & $1 \%$ & $2 \%$ & $1 \%$-points & $185 \%$ \\
\hline P85 (km/h) & 115.54 & 111.83 & -3.71 & $-3 \%$ \\
\hline $\mathrm{P} 15(\mathrm{~km}(\mathrm{~h})$ & 86.84 & 85.55 & -1.28 & $-1 \%$ \\
\hline
\end{tabular}

The results for the speed limit change from 90 to $80 \mathrm{~km} / \mathrm{h}$ on roads with speed cameras are shown in Table 3 . The speed levels were adjusted by a standard increment of $3 \mathrm{~km} / \mathrm{h}$ (due to the angular displacement of the radar measuring equipment), so the levels should be roughly comparable to those from the tube measurements used in other cases. The results indicate that the mean speed decreased from approximately 81 to $75 \mathrm{~km} / \mathrm{h}$. Note that the mean speed before the change was already close to the new speed limit of $80 \mathrm{~km} / \mathrm{h}$. The percentage of drivers exceeding the speed limit increased by 9 percentage points. Observing the change in speed levels in the tails of the distribution, namely, the 15 th and 85 th percentiles, note that P85 decreased by approximately $7 \mathrm{~km} / \mathrm{h}$, slightly more than the decrease in mean speed. P15 decreased slightly less than did the mean speed, by approximately $5 \mathrm{~km} / \mathrm{h}$.

Table 3. Change in various measures when the speed limit was decreased from 90 to $80 \mathrm{~km} / \mathrm{h}$ on rural roads with speed cameras.

\begin{tabular}{|c|c|c|c|c|}
\hline Measure & Before & After & $\begin{array}{l}\text { Change: after- } \\
\text { before }\end{array}$ & $\begin{array}{l}\text { Relative change } \\
(\%)\end{array}$ \\
\hline Mean speed $(\mathrm{km} / \mathrm{h})$ & 81.4 & 75.3 & -6.1 & $-7 \%$ \\
\hline Standard deviation of speed $(\mathrm{km} / \mathrm{h})$ & 6.9 & 5.7 & -1.1 & $-17 \%$ \\
\hline Coefficient of variation & 0.08 & 0.08 & -0.01 & $-10 \%$ \\
\hline $\begin{array}{l}\text { Mean speed of those obeying speed limits } \\
(\mathrm{km} / \mathrm{h})\end{array}$ & 80.6 & 73.9 & -6.7 & $-8 \%$ \\
\hline $\begin{array}{l}\text { Mean speed of those exceeding speed } \\
\text { limits }(\mathrm{km} / \mathrm{h})\end{array}$ & 94.5 & 83.7 & -10.8 & $-11 \%$ \\
\hline Percentage exceeding speed limits & $6 \%$ & $15 \%$ & $9 \%$-points & $166 \%$ \\
\hline $\begin{array}{l}\text { Percentage exceeding speed limits by } 6 \\
\mathrm{~km} / \mathrm{h} \text { or more }\end{array}$ & $1 \%$ & $2 \%$ & $1 \%$ points & $110 \% *$ \\
\hline $\begin{array}{l}\text { Percentage exceeding speed limits by } 30 \\
\mathrm{~km} / \mathrm{h} \text { or more }\end{array}$ & $0.08 \%$ & $0.14 \%$ & $0.06 \%$-points & $69 \% *$ \\
\hline P85 (km/h) & 87.3 & 80.0 & -7.2 & $-8 \%$ \\
\hline P15 (km(h) & 75.4 & 70.4 & -5.0 & $-7 \%$ \\
\hline
\end{tabular}

In Table 4, we can see that the mean speed of all vehicles passing the sites equipped with new speed cameras declined by nearly $7 \mathrm{~km} / \mathrm{h}$, or approximately $8 \%$. In comparison, we see that P85 decreased even more, by nearly $11.5 \mathrm{~km} / \mathrm{h}$, or $11 \%$. This can be compared with the national evaluation of speed cameras (Swedish Road Administration, 2009), according to which P85 fell by approximately $10 \%$. P15 fell by nearly $4 \mathrm{~km} / \mathrm{h}$, or 
approximately $5 \%$. All studied speed violation measures declined sharply. The percentage of drivers exceeding the speed limit declined from over $40 \%$ before the speed cameras were installed to $10 \%$ after, a $75 \%$ decrease that agrees well with the results of the Swedish Road Administration's (2009) national evaluation. The percentage exceeding the speed limit by $6 \mathrm{~km} / \mathrm{h}$ or more decreased by 21 percentage points. As noted earlier in connection with both the national evaluation and the speed distribution shown in Fig. 3, those who drove at the highest speeds were affected the most by the installation of speed cameras.

Table 4. Change in various measures when new speed cameras were introduced on roads with a speed limit of $90 \mathrm{~km} / \mathrm{h}$.

\begin{tabular}{|c|c|c|c|c|}
\hline Measure & Before & After & $\begin{array}{l}\text { Change: after- } \\
\text { before }\end{array}$ & $\begin{array}{l}\text { Relative change } \\
(\%)\end{array}$ \\
\hline Mean speed $(\mathrm{km} / \mathrm{h})$ & 89.5 & 82.6 & -6.9 & $-8 \%$ \\
\hline Standard deviation of speed $(\mathrm{km} / \mathrm{h})$ & 12.0 & 8.3 & -3.7 & $-31 \%$ \\
\hline Coefficient of variation & 0.13 & 0.10 & -0.03 & $-25 \%$ \\
\hline $\begin{array}{l}\text { Mean speed of those obeying speed limits } \\
(\mathrm{km} / \mathrm{h})\end{array}$ & 82.3 & 81.1 & -1.2 & $-2 \%$ \\
\hline $\begin{array}{l}\text { Mean speed of those exceeding speed } \\
\text { limits }(\mathrm{km} / \mathrm{h})\end{array}$ & 99.9 & 95.7 & -4.2 & $-4 \%$ \\
\hline Percentage exceeding speed limits & $41 \%$ & $10 \%$ & $-31 \%$-points & $-75 \%$ \\
\hline $\begin{array}{l}\text { Percentage exceeding speed limits by } 6 \\
\mathrm{~km} / \mathrm{h} \text { or more }\end{array}$ & $24 \%$ & $3 \%$ & $-21 \%$-points & $-86 \%$ \\
\hline $\begin{array}{l}\text { Percentage exceeding speed limits by } 30 \\
\mathrm{~km} / \mathrm{h} \text { or more }\end{array}$ & $0.5 \%$ & $0.05 \%$ & $-0.5 \%$-points & $-91 \%$ \\
\hline P85 (km/h) & 101.1 & 89.6 & -11.5 & $-11 \%$ \\
\hline P15 (km(h) & 80.5 & 76.7 & -3.8 & $-5 \%$ \\
\hline
\end{tabular}

For all measures presented above, the same tendency concerning P85 and P15 can be observed, i.e., the relative and absolute changes in P85 are greater than the comparable changes in P15. This effect is much greater when new speed cameras are introduced (Table 4) than when only the speed limit is lowered (Tables 2 and 3). When lowering the speed limit on a road with speed cameras, drivers seem to adapt well to the new speed limit.

\subsection{Relative risks}

Table 5 shows the estimated change in the number of fatal, severe, and minor injured. The changes in risk are calculated using the Power model (Elvik et al., 2004) and the powers used are $d=4.5$ for the number of fatal, $d=$ 3.0 for the number of severe, and $d=1.5$ for the number of minor injuries.

Table 5. Change in risk of injured of differing severities with three traffic safety measures: speed limit change from 110 to $100 \mathrm{~km} / \mathrm{h}$ on roads without speed cameras, speed limit change from 90 to $80 \mathrm{~km} / \mathrm{h}$ on roads with speed cameras, and introduction of new speed cameras on roads with a speed limit of $90 \mathrm{~km} / \mathrm{h}$. Risk changes calculated using the Power model.

\begin{tabular}{llll}
\hline Severity & $\begin{array}{l}\text { Decreased speed } \\
\text { limit from } 110 \\
\text { to } 100 \mathrm{~km} / \mathrm{h}\end{array}$ & $\begin{array}{l}\text { Decreased speed } \\
\text { limit from } 90 \text { to } \\
80 \mathrm{~km} / \mathrm{h}, \text { with } \\
\text { existing cameras }\end{array}$ & $\begin{array}{l}\text { Speed limit of } \\
90 \mathrm{~km} / \mathrm{h} \text { with } \\
\text { new cameras }\end{array}$ \\
\hline Minor injury & $-4.6 \%$ & $-10.9 \%$ & $-11.4 \%$ \\
Severe injury & $-8.9 \%$ & $-20.7 \%$ & $-21.4 \%$ \\
Fatality & $-13.1 \%$ & $-29.4 \%$ & $-30.4 \%$ \\
\hline
\end{tabular}

Results indicate that the largest decreases in injury risk can be achieved when new speed cameras are introduced, due to the larger decrease in mean speed (see Table 4; compared to Tables 2, 3). When new speed cameras were introduced on roads with a speed limit of $90 \mathrm{~km} / \mathrm{h}$, the mean speed decreased by almost $7 \mathrm{~km} / \mathrm{h}$ or $8 \%$, and the number of fatalities decreased by an estimated $30.4 \%$ and the number of severely injured by $21.4 \%$. On roads where the speed limit decreased from 110 to $100 \mathrm{~km} / \mathrm{h}$, the mean speed decreased by approximately $3 \mathrm{~km} / \mathrm{h}$ or $3 \%$, and the number of fatalities decreased by an estimated $13.1 \%$ and the number of severely injured by $8.9 \%$. 


\section{Discussion}

This study sought a better understanding of the relationship between traffic safety measures and speed distribution, to obtain a better basis for planning and evaluating various road safety measures. The study compares changes in the speed distribution and estimated accident risk for three different measures: speed limit change from 110 to $100 \mathrm{~km} / \mathrm{h}$ on roads without speed cameras, speed limit change from 90 to $80 \mathrm{~km} / \mathrm{h}$ on roads with speed cameras, and introducing new speed cameras on roads with a speed limit of $90 \mathrm{~km} / \mathrm{h}$. The results indicate that introducing new speed cameras resulted in a larger reduction of average speed than did decreasing the speed limit by $10 \mathrm{~km} / \mathrm{h}$, at least at the camera sites. When new speed cameras were introduced on roads with a speed limit of $90 \mathrm{~km} / \mathrm{h}$, the mean speed decreased by almost $7 \mathrm{~km} / \mathrm{h}$ or $8 \%$. On roads with existing cameras where the speed limit changed from 90 to $80 \mathrm{~km} / \mathrm{h}$, the mean speed decreased by approximately $6 \mathrm{~km} / \mathrm{h}(7 \%)$, while on roads where the speed limit decreased from $110 \mathrm{~km} / \mathrm{h}$ to $100 \mathrm{~km} / \mathrm{h}$, the mean speed decreased by only approximately $3 \mathrm{~km} / \mathrm{h}$ or $3 \%$, despite the fact that we selected the measurement sites with the largest decrease. Results of the national evaluation of the new speed limits (Vadeby and Forsman, 2013) indicate that, in general, when reducing the speed limit by $10 \mathrm{~km} / \mathrm{h}$ on $2+1$ roads and rural roads with a speed limit of $110 \mathrm{~km} / \mathrm{h}$, the mean car speed decreases by $2 \mathrm{~km} / \mathrm{h}$. This paper also demonstrates that speed cameras reduce the standard deviation of speed and the percentage of drivers exceeding the speed limit by far more than they reduce the mean speed. The speed distribution indicates a larger displacement to the left at high speeds, meaning that those who drive at the highest speeds reduce their speed the most. These results are in line with recent findings concerning average speed enforcement. Soole et al. (2013), who reviewed the effect of average speed enforcement, concluded that "the approach has been noted as a particularly effective countermeasure in reducing excessive speeding behavior".

The results also indicate that, due to the accompanying speed reductions, the estimated change in injury risk is considerably greater for the introduction of new speed cameras than for reducing speed limits. However, this estimated risk reduction is based on the Power model, which considers only changes in mean speed. The true difference in risk reduction is possibly even greater, since speed cameras also change the speed distribution, causing those who drive at the highest speeds to reduce their speed the most. No currently established model can take this into account. The individual risk models reviewed by Aarts and Schagen (2006) were developed from different types of data and each produces quite different results. It can also be noted that in Elvik (2013) a reparameterisation of the Power model was done. It is beyond the scope of this study to compare our results to this new model. However, since only relative risk-changes are studied and the models are rather similar, the assessment is that this does not affect the results and conclusions of our study to any significant extent.

One objection related to speed variation is that the measures are often generic, such as variance or percentage of drivers exceeding the speed limit. Shinar (1998) notes that most studies estimate the variance across days, which means that a large variance may reflect speed variations due to differences in speed between high- and lowtraffic-volume periods. To avoid this problem, alternative measures are suggested by Lu and Chen (2009) and Munden (1967) that reflect the speed variation between adjacent vehicles. Vadeby and Forsman (2012b) compare the traditional standard deviation of speed calculated over the entire time period (several days), the standard deviation calculated on an hourly basis, ASD i.e. (Average Speed Difference, Lu and Chen, 2009) and the measure suggested by Munden. The data used for the comparison are the same as used in the present study, i.e., collected on roads where the speed limit decreased from 110 to $100 \mathrm{~km} / \mathrm{h}$. Vadeby and Forsman's (2012) results indicate the difficulty of drawing any general conclusions from the comparison. However, for the roads studied, there were only minor differences between an overall standard deviation of speed and a standard deviation calculated on an hourly basis, though there may be differences in the overall standard deviation and the variation between adjacent vehicles.

In conclusion, the results of this and earlier studies indicate a need for further research, examining both speed variation measures and the relationship between speed distribution change and traffic safety.

\section{Acknowledgements}

The authors are grateful to the Swedish Transport Administration for funding the original study. 


\section{References}

Aarts, L., and Schagen, I. van (2006). Driving speed and the risk of road crashes: A review. Accident Analysis and Prevention, 38, 215-224.

Andersson, G., and Nilsson, G. (1997). Speed limits, speeds and safety. Linköping. Sweden: VTI.

Cirillo, J. A. (1968). Interstate system accident research study II, interim report II. Public roads 35 (3), 71-76.

Elvik, R., Christensen, P., and Amundsen, A. H. (2004). Speed and road accidents: An evaluation of the power model. TØI report no. 740/2004. Oslo: TØI.

Elvik, R. (2013). A re-parameterisation of the Power Model of the relationship between the speed of traffic and the number of accidents and accident victims. Accident Analysis and Prevention, No 50, 854-860

Finch, D. J., Kompfner, P., Loockwood, C. R., and Maycock, G. (1994). Speed, speed limits and accidents. Project report no. 58. Transport Research Laboratory TRL, Crowthorne, Berkshire.

Kloeden, C. N., Ponte, G., and McLean, A. J. (2001). Travelling speed and the risk of crash involvement on rural roads. Report no. CR 204. Adelaide, Australia: Road Accident Research Unit, Adelaide University.

Lu, F. Chen, X. (2009) Analysing the speed dispersion influence on traffic safety. 2009 Internal Conference on Measuring Technology and Mechatronics Automation.

Maycock, G., Brocklebank, P.J., Hall, R.D. (1998). Road layout design standards and driver behaviour. TRL Report No. 332. Transport Research Laboratory TRL, Crowthorne, Berkshire.

Munden, J. M. (1967). The relation between a driver's speed and his accident rate. RRL Report LR 88. Road Research Laboratory, Crowthorne, Berkshire.

Nilsson, G. (2004). Traffic safety dimensions and the power model to describe the effect of speed on safety. Bulletin 221. Lund, Sweden: Lund Institute of Technology, Department of Technology and Society, Traffic Engineering.

Quimby, A., Maycock, G., Palmer, C., and Buttress, S. (1999). The factors that influence a driver's choice of speed: A questionnaire study. TRL report no. 325. Crowthorne, UK: Transport Research Laboratory.

Shinar, D. (1998). Speed and crashes: A controversial topic and an elusive relationship. Appendix B in Managing speed: Review of current practice for setting and enforcing speed limits. Special report no. 254. Washington, DC: Transportation Research Board.

Solomon, D., 1964. Crashes on main rural highways related to speed, driver and vehicle. In: Bureau of Public Roads. U.S. Department of Commerce. United States Government Printing Office, Washington, D.C.

Soole, D. W., Watson, B. C., and Fleiter, J.J. (2013). Effects of average speed enforcement on speed compliance and crashes: A review of the literature. Accident Analysis and Prevention, 54, 46-56.

Swedish Road Administration (2009). The effects of automated road safety cameras on speed and traffic safety. Publication no. 2009:62. Borlänge, Sweden: Swedish Road Administration.

Vadeby, A., Forsman, Å. (2010). Utvärdering av nya hastighetsgränssystemet: Effekter på hastigheter, etapp 1 [Evaluation of the new speed limits: the effect on vehicle speeds, Phase 1]. VTI notat 14-2010. VTI, Linköping, Sweden. In Swedish, summary in English.

Vadeby, A., Forsman, ̊. (2012a). Utvärdering av nya hastighetsgränssystemet: Effekter på hastighet, etapp 2 [Evaluation of the new speed limits: the effect on vehicle speeds, Phase 2]. VTI notat 16-2012. VTI, Linköping, Sweden . In Swedish, summary in English.

Vadeby, A., and Forsman, ̊. (2012b). Hastighetsspridning och trafiksäkerhet [Traffic safety and speed distribution]. VTI report no. 746-2012. Linköping, Sweden: VTI. In Swedish, summary in English.

Vadeby, A., and Forsman, ̊. (2013). Speed management in Sweden: Evaluation of a new speed limit system. In Proceedings of the 16th International Conference on Road Safety on Four Continents, Beijing, China, 15-17 May. 